\title{
Compensating the performance of permanent magnet synchronous machines for fully electric vehicle using LPV control
}

\author{
Hassam Muazzam ${ }^{1}$, Mohamad Khairi Ishak ${ }^{2}$, Athar Hanif ${ }^{3}$ \\ ${ }^{1,2}$ School of Electrical and Electronic Engineering, Engineering Campus, Universiti Sains Malaysia, Nibong Tebal, \\ 14300, Penang, Malaysia \\ ${ }^{3}$ Center for Automotive Research, The Ohio State University, Columbus, 432122 United States of America (U.S.A)
}

\begin{tabular}{l} 
Article Info \\
\hline Article history: \\
Received Mar 3, 2021 \\
Revised May 20, 2021 \\
Accepted Jun 22, 2021 \\
\hline
\end{tabular}

\section{Keywords:}

$\mathrm{H} \infty$

Linear parameter varying

Linear quadratic integral

Permanent magnet synchronous machines

Proportional integral derivative

\begin{abstract}
The state-of-the-art robust Ho linear parameter-varying controller is designed for wide speed operating range for non-linear mathematical model of permanent magnet synchronous machines (PMSM) in d-q reference frame for fully electric vehicle. This study propose polytopic approach using rotor speed as scheduling variable to reformulate mathematical model of PMSM into linear parameter varying (LPV) form. The weights were optimized for sensitivity and complementary sensitivity function. The simulation results illustrate fast tracking and enhanced performance of the proposed control technique over wide range of rotor speed. Moreover, as part of this work, the results of $\mathrm{H} \infty$ linear parameter varying controller is validated by comparing it with linear quadratic integrator and proportional integral derivative (PID) control techniques to show the effectiveness of the proposed control technique.
\end{abstract}

This is an open access article under the CC BY-SA license.

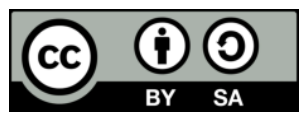

\section{Corresponding Author:}

Mohamad Khairi Ishak

School of Electrical and Electronic Engineering

Engineering Campus, Universiti Sains Malaysia

Nibong Tebal, 14300, Penang, Malaysia

Email: khairiishak@usm.my

\section{INTRODUCTION}

Legislative authorities around the world, with the vision of zero-emission vehicles and rapid decline of fossil fuels, are supporting automotive industry to make substantial investments on the deployment of electric vehicles (EV) viable and sustainable right from the beginning. An ambitious paradigm shift has been projected from pure ICE vehicles to FEV and plug-in hybrid electric vehicle (PHEV), which seems to be pragmatic from the $67 \%$ growth of the vehicles till 2109 [1]. Due to which car industry is going under radical evolution in electrified powertrain; ranging from FEV, PHEV and hybrid electric vehicle (HEV). This transformation has introduced diverse impacts on various vehicle dynamics especially on the electrified powertrain systems. Due to iterated start and stop, high reaching acceleration, and deceleration; hill climbing with variations of speed and cruising high reaching, [2] powertrain renders interesting speed control challenges for electric traction motors being the pivotal component. A validated controller always includes constant power and torque operating region for traction motor used in EV as depicted in Figure 1. Due to its high performance, power density, high dynamic response, reliability, technological maturity, and a gap for advancement in controller design, PMSM is the most appropriate option for traction motor among induction motor (IM), direct current (DC) and switched reluctance motor (SRM) machines, as illustrated in Table 1 based on the requisite characteristics [3]-[6]. 


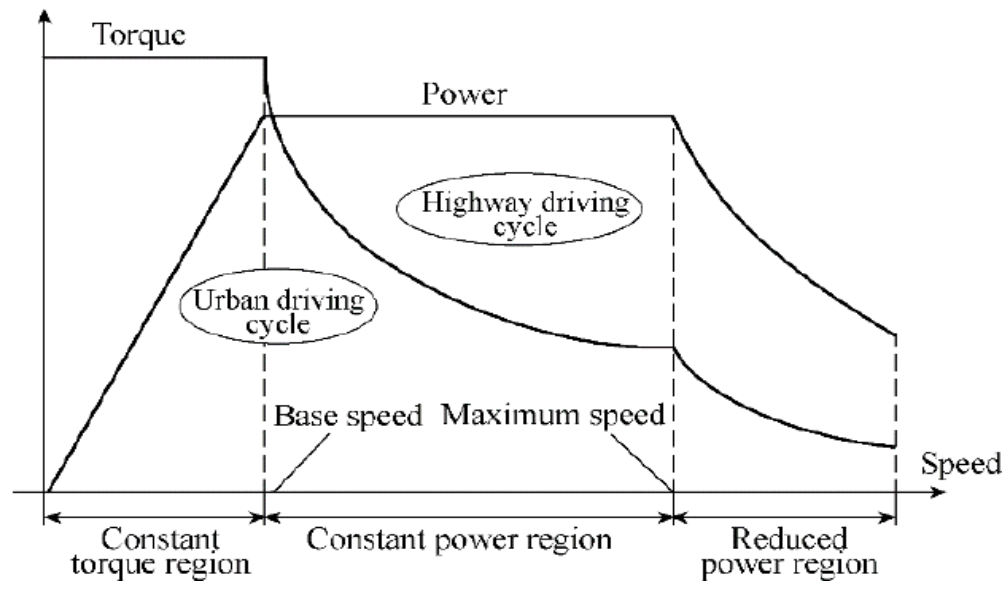

Figure 1. Speed-torque Xtics for EV

Table 1. Xtic of traction motors

\begin{tabular}{ccccccc}
\hline & Power density & Reli-ability & Controll-ability & Technological Maturity & Efficiency & Total \\
\hline DC & 10 & 12 & 20 & 20 & 10 & 72 \\
PMSM & 20 & 16 & 16 & 16 & 20 & 88 \\
IM & 14 & 20 & 20 & 20 & 14 & 88 \\
SRM & 14 & 20 & 12 & 16 & 14 & 76 \\
\hline
\end{tabular}

PMSM can be seen as an alternating current (AC) counterpart of brushless DC motor with the change lying in field excitation provided by the permanent magnets and sinusoidal back electromotive force (EMF). Neodymium iron boron (NdFeb) is widely employed as permanent magnets due to its magnetic characteristics (remenance and coercivity) and price reduction of the material. The PMSM is classified in two types according to the direction of magnetic flux generated by PMs: Axial and radial flux type; the difference lies in crossing the air gap by magnetic flux in axial and radial direction consequently. The radial flux type is further categorized into two classes; SMPM and interior permanent magnet (IPM) motor with the main difference of magnets being mounted on the rotor in SMPM widely used in machinetools drives while in IPM, these are buried inside the rotor [7]. SMPMs have limited capabilities for high speed operation while IPMs have greater mechanical strength for high speed variable operation because of which are most commonly seen being used in automotive industry. The PMSM has been used in electrified power train by Honda (Accord, Fit, and Civic), Toyota (Reva4, Camry And Prius), Fiat (Peogeot ION), Hyundai (Blueon), Nissan (leaf and Altera), Chevrolet (Volt), Tata (Indica), build your dream (BYD) (F3M and e6), and Mitsubishi (Miev) [8]. The PMSM machine is not limited to automotive industry but has widely emerged in aerospace and marine industries as well.

In recent years, various modern, traditional, and intelligent control strategies have been explored to increase the control of PMSM. Sliding mode control (SMC) [9] creates chattering problem, which results in poor steady state performance when evaluated for the motor control. To increase the performance and robustness by reducing the chattering problem, fractional calculus (differential and integration) [10] and fuzzy adaptive sliding mode control [11] have been introduced but the degree of complexity also increases. extended kalman filter (EKF) based fuzzy logic controllers can also be a good choice but increases the computational cost [12], [13]. Disturbance observer has been simulated to improve motor control, but unfortunately contingent to accurate nonlinear dynamics of motor [14]. Although adaptive internal motor control [15] offers disturbance rejection capability for motor control, fails to consider control input saturation reducing the performance. Hळ controller with loop shaping design procedure (LSDP) has also been discussed [16], [17], but when the trajectory goes beyond the close vicinity, the stability is not guaranteed.

In recent past, field oriented control (FOC), a type of venture capital (VC), is quite popularly used for high performance applications of motor control due to its dynamic speed response, high reliability, and strong robustness and provides wide speed range with high torque at zero speed [18], [19]. Similarly after $\mathrm{VC}$, direct torque control (DTC) is making pace for panacea of torque and speed control challenges due to high efficiency, low losses and working in stationary coordinates [20], [21]. Still, DTC has not been proposed for PMSM as it suffers for low speed torque and flux estimation control, torque ripples, and high current.

Shamma and Athans [22], [23] in early 90's first introduced LPV (gain scheduling) model for systematic analysis whose linear state space matrices depended on time varying parameters. Many authors 
[24]-[31], working on speed and torque control have preferred FOC based LPV control due to the analysis of non-linear mathematical model of PMSM in d-q axis by formulating the motor dynamics in LPV form. Thus, LPV control technique can provide quantifiable performance and robustness as compared to other controllers. The aforementioned LPV work is commendable for speed tracking despite that most of the authors have missed out torque load effects on the speed control. Herein, LPV Hœ controller for catering speed tracking challenge takes into account the torque load with polytopic approach of LPV and the results are compared with PID and linear quadratic regulator (LQI) controllers. The remainder of this article is structured in six sections; section 2 gives an overview of mathematical model PMSM, section 3 discusses design of LPV implementation, section 4 demonstrates the experimental results and section 5 presents the conclusion.

\section{MATHEMATICAL MODEL PMSM}

The mathematical model of PMSM in d-q reference frame can be represented in form of voltage and flux linkage (1) to (7). In (7) the first term is magnetic torque while the second term represents the reluctance torque. The mathematical model being the most exclusive [24], [32]-[34] already been used to formulate into LPV form has been utilized.

$$
\begin{aligned}
& \frac{d}{d t} \psi_{s d}=-V_{s d}+R_{s}+i_{s d}+p w_{m} \psi_{s q} \\
& \frac{d}{d t} \psi_{s q}=-V_{s q}+R_{s}+i_{s q}+p w_{m} \psi_{s d} \\
& \frac{d}{d t} i_{s d}=\frac{1}{L_{s d}}\left(V_{s d}-R_{s} i_{s d}+L_{s q} \psi w_{m} i_{s q}\right) \\
& \frac{d}{d t} i_{s q}=\frac{1}{L_{s q}}\left(V_{s q}-R_{s} i_{s q}+L_{s d} \psi w_{m} i_{s d}+\lambda \psi w_{m}\right) \\
& \frac{d}{d t} w_{m}=\frac{1}{J}\left(\tau_{e}-\tau_{L}-B w_{m}\right) \\
& \frac{d}{d t} \theta_{m}=w_{m} \\
& \tau_{e}=\frac{3}{2} p\left(i_{s q} \lambda+\left(L_{s d}-L_{s q}\right) i_{s d} i_{s q}\right)
\end{aligned}
$$

\section{CONTROLLER DESIGN}

\subsection{Linear parameter varying}

LPV depends on exogenous non-stationary parameter. The first step is to transform the nonlinear mathematical model of PMSM into linear LPV form. The generalized representation in state-space representation of LPV system is shown in (8).

$$
\begin{aligned}
& \dot{x}=A(\theta) x+B(\theta) u \\
& y=C(\theta) x+D(\theta) u
\end{aligned}
$$

The goal is to design LPV controller, which adjusts the motor dynamics based on information of rotor speed. In this case, scheduling parameter $(\mathrm{t})$ is the speed of rotor and can be stated as: $\theta=w_{m}$ for polytopic LPV system. The PMSM model will no longer be nonlinear with respect to rotor speed Wm. The state space form of PMSM in state form can be defined in (9)-(11).

$$
\begin{aligned}
& A=\left(\begin{array}{cc}
-\frac{R_{s}}{L_{d}} & p w_{m} \frac{L_{d}}{L_{q}} \\
-p w_{m} \frac{L_{q}}{L_{d}} & -\frac{R_{s}}{L_{q}}
\end{array}\right) \\
& B=\left(\begin{array}{cc}
\frac{1}{L_{d}} & 0 \\
0 & \frac{1}{L_{q}}
\end{array}\right),
\end{aligned}
$$




$$
C=\left(\begin{array}{ll}
1 & 0 \\
0 & 1
\end{array}\right)
$$

Where $\mathrm{A}$ is the system matrix, $\mathrm{B}$ is the input matrix and $\mathrm{C}$ is the output matrix. Input vector $\mathrm{u}$ and state vector $\mathrm{x}$ is defined as [Vd Vq]T and [id iq]T respectively. The augmented plant state-space data is obtained in (12):

$$
\begin{aligned}
& \left(\begin{array}{ll}
A(\theta(t)) & B(\theta(t)) \\
C(\theta(t)) & D(\theta(t))
\end{array}\right)=\sum_{i=1}^{N} \propto_{i}\left(\begin{array}{ll}
A_{i} & B_{i} \\
C_{i} & D_{i}
\end{array}\right) \\
& \theta(t)=\sum_{i=1}^{N} \propto_{i}(t) \theta_{v i}, \quad \propto_{i} \geq 0, \\
& \sum_{i=1}^{N} \propto_{i}(t)=1 .
\end{aligned}
$$

The designed LPV structure contains weights Wi and Wy of sensitivity and complementary sensitivity respectively as shown in Figure 2. The weighting function affects to achieve desired performance. The functions relate to tracking and disturbance rejection performance is being as:

$$
\frac{1}{W_{i}}=\frac{s+w_{b} A}{\frac{1}{M} s+w_{b}}
$$

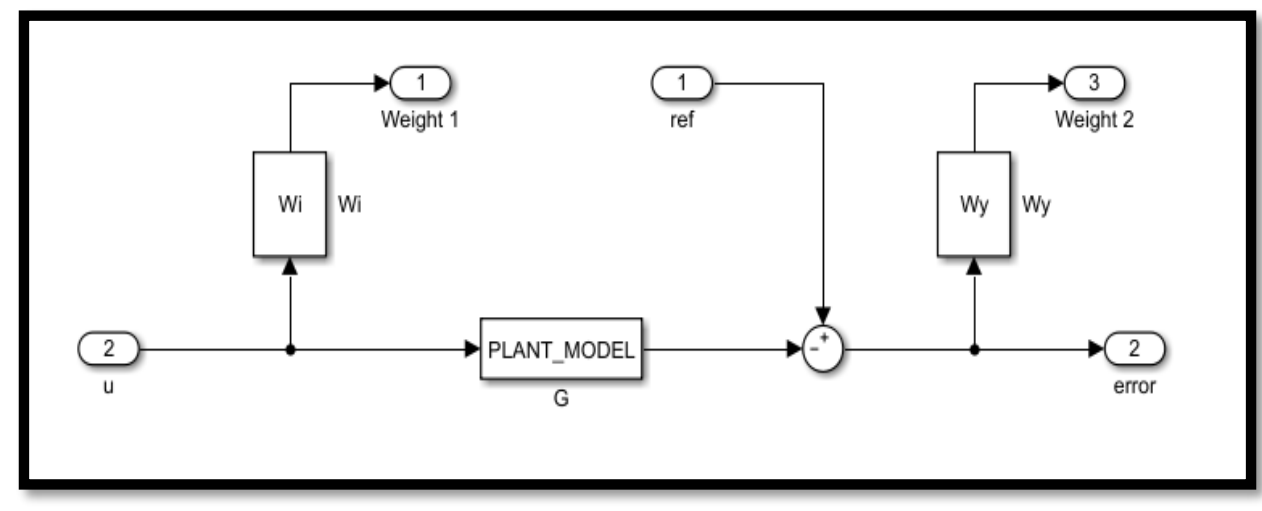

Figure 2. Basic system with weights

The $\mathrm{M}$ is for robust stability, a for tracking error and wb for customizing response time. Wy static weight to limit control action.

\subsection{Proportional integral derivative}

PID or modified PID are most commonly used controller in industrial applications due to robustness and easy to implement properties [34], [35]. It depends on the corrected coefficient values of proportional, integral, and derivative control terms illustrated in (13). The proportional and integral terms usually decrease the rise time and steady state error while increasing the overshoot. Contrary to derivative control term decreasing the overshoot and settling time. Mathematically, it can be represented as;

$$
u(t)=K_{p} e(t)+K_{i} \int_{0}^{t} e(t) d t+K_{d} \frac{d e(t)}{d t}
$$

where $\mathrm{Kp}, \mathrm{Ki}$, and $\mathrm{Kd}$ are coefficients for proportional, integral and derivative values.

\subsection{Proportional integral derivative}

The LQI controller in (14) is state optimal controller derived from LQR by adding integrator for reduction in steady state error, thus enhancing the performance of the controller.

$$
J(u)=\int_{0}^{\infty}\left\{x^{T} Q x+u^{T} R u\right\} d t
$$




$$
\mathrm{U}=-\mathrm{Kx}=-\mathrm{K}\left[\mathrm{x} \mathrm{x}_{\mathrm{i}}\right]
$$

Where $\mathrm{u}$ is the input, $\mathrm{K}$ is the optimal gain value, $\mathrm{x}_{\mathrm{i}}$ is the integral output and $\mathrm{x}$ are the states of the system. Its basic operation is to minimize a cost function. Where $\mathrm{Q}$ is a symmetric positive definite weighting matrix for states of the system and $\mathrm{R}$ is a symmetric positive definite weighting matrix for inputs of the system.

\section{RESULTS AND DISCUSSION}

The LPV Ho controller was simulated using matrix laboratory MATLAB/SIMULINK for PMSM, the closed loop system using the motor parameters in Table 2 is augmented with weighting function. The rotor speed as scheduling variable has been used for two vertex plant. Rotor speed tracking simulations of PMSM using LPV has been compared with LQI and PID at 200, 300, and $800 \mathrm{rpm}$; the results clearly show better tracking and performance in context of settling time, rise time illustrated in Figure 3 . For tracking the q-coordinates, current was designed to be zero as shown in Figure 4.

Table 2. Motor parameters

\begin{tabular}{lcc}
\hline Stator Resistance & $\mathrm{Rs}$ & $0.8 \Omega$ \\
\hline q-axis Inductance & $\mathrm{Lq}$ & $0.003 \mathrm{H}$ \\
d-axis Inductance & $\mathrm{Ld}$ & $0.003 \mathrm{H}$ \\
Flux Linkage & lambda & $85.45 \mathrm{e}-3 \mathrm{~Wb}$ \\
Poles & $\mathrm{P}$ & 4 \\
Moment of Inertia & $\mathrm{Jm}$ & $235 \mathrm{e}-3 \mathrm{Kg} \cdot \mathrm{m}^{2}$ \\
Viscous Damping & $\mathrm{B}$ & 0 \\
\hline
\end{tabular}

It can be seen that the linear controllers are only efficient for designed phase margins, most of the tuning of PID controllers are done manually so they are poorly tuned in practice. That is why it is generally not considered as a correct technique as it fails in providing a quantifiable measure for the robustness of the controller. On the other hand, LPV works for all phase margins. After applying $1 \mathrm{Nm}$ load, the behavior of rotor speed can be seen in Figure 5. LPV control compensates the load torque most effectively.

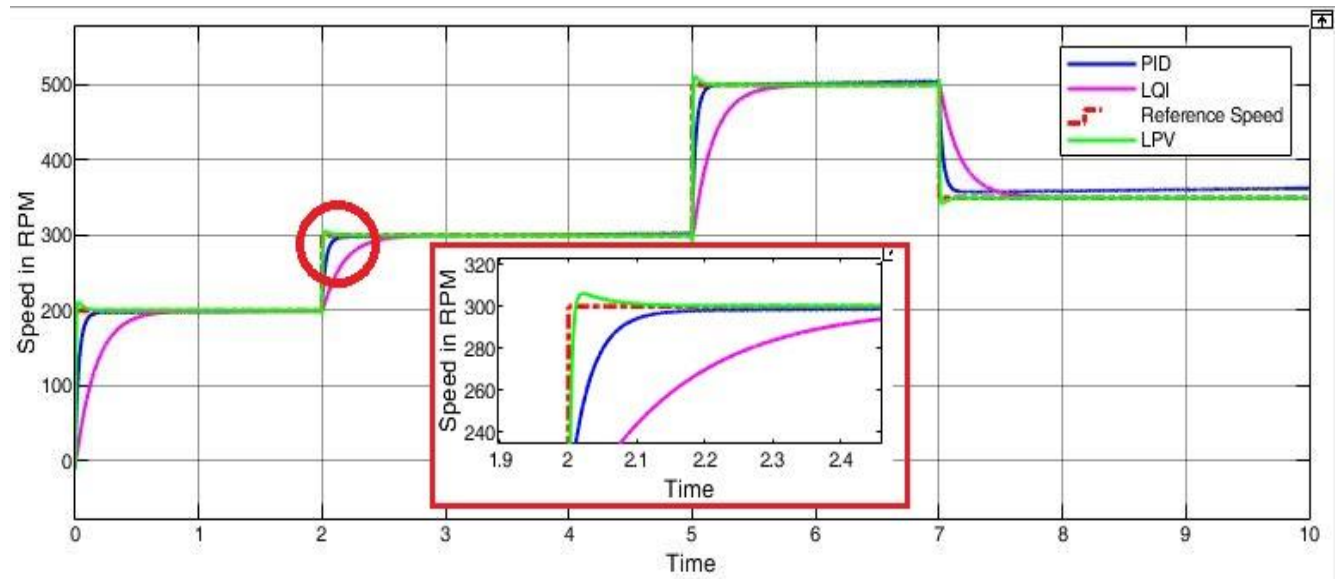

Figure 3. Comparison of tracking of rotor speed using LPV, LQI, and PID

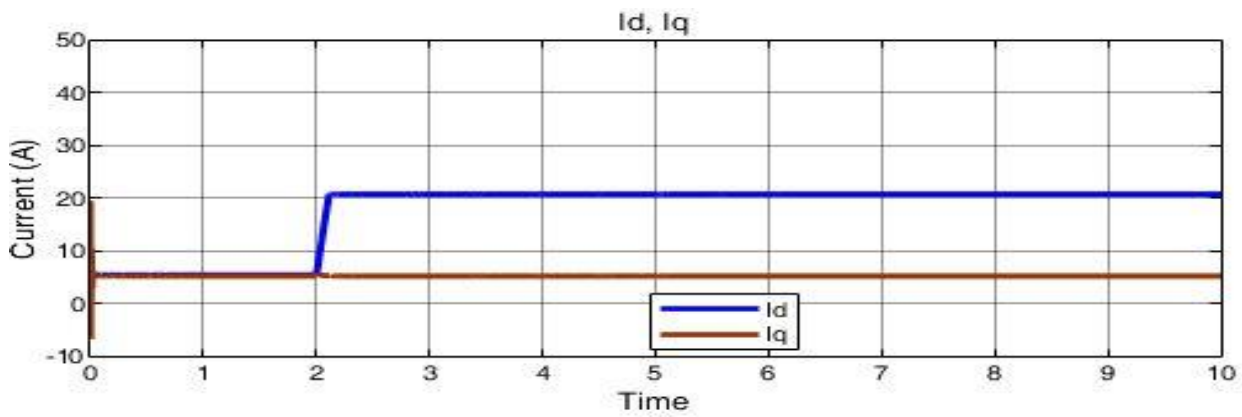

Figure 4. Motor currents Id and Iq 


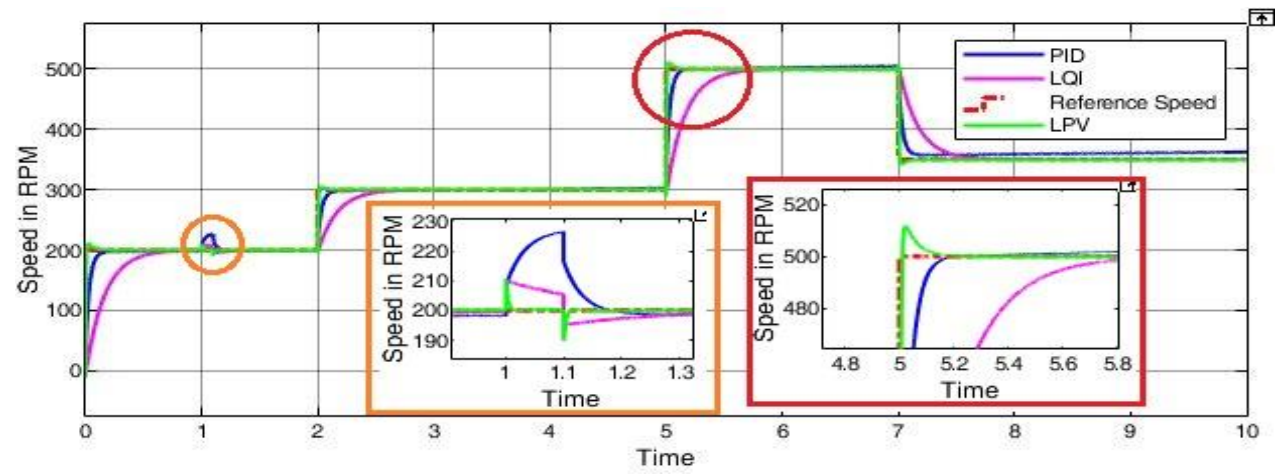

Figure 5. Comparison of tracking of rotor speed using LPV, LQI, and PID after apply load torque at LPV

\section{CONCLUSION}

In this work, linear parameter varying based control technique has been designed for nonlinear PMSM to improve its performance for the application in fully electric vehicle. The rotor speed was used as a scheduling variable in the design process of LPV controller. The weights were optimized to achieve fast tracking and high performance. The simulation result of LPV when compared with PID and LQI for the control of PMSM proves to be better perfromed for systems required in FEV.

\section{ACKNOWLEDGEMENTS}

The authors would like to thank Universiti Sains Malaysia for providing the financial support under the research grant research at undergraduate institutions (RUI) (1001/PELECT/8014049).

\section{REFERENCES}

[1] Virta, "The Global Electric Vehicle Market In 2021: Statistics \& Forecasts", 2021, [Online]. Available: https://www.virta.global/global-electric-vehicle-market.

[2] E. R. Adlard, M. Ehsani, Y. Gao, S. Longo, and K. M. Ebrahimi, "Modern Electric Hybrid Electric and Fuel Cell Vehicles (3rd Edn),' Chromatographia, vol. 82, p. 793, 2019.

[3] W. Wang, X. Chen, and J. Wang, "Motor/Generator Applications in Electrified Vehicle Chassis-A Survey," in IEEE Transactions on Transportation Electrification, vol. 5, no. 3, pp. 584-601, September 2019, doi: 10.1109/TTE.2019.2934340.

[4] M. Zeraoulia, M. E. H. Benbouzid, and D. Diallo, "Electric Motor Drive Selection Issues for HEV Propulsion Systems: A Comparative Study," in IEEE Transactions on Vehicular Technology, vol. 55, no. 6, pp. 1756-1764, Nov. 2006, doi: 10.1109/TVT.2006.878719.

[5] I. López, E. Ibarra, A. Matallana, J. Andreu, and I. Kortabarria, "Next generation electric drives for HEV/EV propulsion systems: Technology, trends and challenges," Renewable and Sustainable Energy Reviews, vol. 114, p. 109336, October 2019, doi: 10.1016/j.rser.2019.109336.

[6] J. de Santiago, et al., "Electrical Motor Drivelines in Commercial All-Electric Vehicles: A Review," in IEEE Transactions on Vehicular Technology, vol. 61, no. 2, pp. 475-484, Feb. 2012, doi: 10.1109/TVT.2011.2177873.

[7] T. J. Woolmer and M. D. McCulloch, "Analysis of the Yokeless and Segmented Armature Machine," 2007 IEEE International Electric Machines \& Drives Conference, 2007, pp. 704-708, doi: 10.1109/IEMDC.2007.382753.

[8] S. J. Rind, Y. Ren, Y. Hu, J. Wang, and L. Jiang, "Configurations and control of traction motors for electric vehicles: A review," in Chinese Journal of Electrical Engineering, vol. 3, no. 3, pp. 1-17, December 2017, doi: 10.23919/CJEE.2017.8250419.

[9] J. Qian J, C. Ji, N. Pan, and J. Wu, "Improved Sliding Mode Control for Permanent Magnet Synchronous Motor Speed Regulation System,'” Applied Sciences, vol. 8, no. 12, p. 2491, November 2018, doi: 10.3390/app8122491.

[10] F. M. Zaihidee, S. Mekhilef, and M. Mubin, "Application of Fractional Order Sliding Mode Control for Speed Control of Permanent Magnet Synchronous Motor," in IEEE Access, vol. 7, pp. 101765-101774, 2019, doi: 10.1109/ACCESS.2019.2931324.

[11] N. Y. Han, Z. G. Li, and Q. Zou, "Fuzzy Adaptive Sliding Mode Control of Chain Servo System," 2019 Chinese Control Conference (CCC), 2019, pp. 2725-2730, doi: 10.23919/ChiCC.2019.8866234.

[12] J. Yang, et al., "EKF Based Fuzzy PI Controlled Speed Sensorless Power Optimal Control of a Direct Drive Power System," in IEEE Access, vol. 7, pp. 61610-61619, 2019, doi: 10.1109/ACCESS.2019.2912431.

[13] L. J. Mohana and H. N. Suresh, "A robust EKF based speed estimator and Fuzzy optimization technique for sensorless induction motor drives," International Journal of Power Electronics and Drive Systems, vol. 8, no. 1, pp. 147-155, March 2017, doi: 10.11591/ijpeds.v8i1.pp147-155. 
[14] W. Kim, D. Shin, and C. C. Chung, "Microstepping Using a Disturbance Observer and a Variable Structure Controller for Permanent-Magnet Stepper Motors," in IEEE Transactions on Industrial Electronics, vol. 60, no. 7, pp. 2689-2699, July 2013, doi: 10.1109/TIE.2012.2198033.

[15] X. Shao, J. Zhang, Z. Zhao, and X. Wen, "Adaptive internal model control of permanent magnet synchronous motor drive system," 2005 International Conference on Electrical Machines and Systems, vol. 3, pp. 1843-1846, 2005, doi: 10.1109/ICEMS.2005.202880.

[16] N. Ban, H. Ogawa, M. Ono, and Y. Ishida, "A servo control system using the loop shaping design procedure," World Academy of Science, Engineering and Technology, vol. 60, 2009.

[17] S. S. Acevedo, E. Giraldo, and D. Giraldo, "Speed Control of Induction Motor Using Robust Control with LSDP," 2008 Electronics, Robotics and Automotive Mechanics Conference (CERMA '08), 2008, pp. 350-353, doi: 10.1109/CERMA.2008.73.

[18] L. Yunfei and Z. Chengning Z, "A Comparative Experimental Analysis of PMSM between Deadbeat Prediction Current Control and Field-oriented Control,' Energy Procedia, vol. 158, pp. 2488-2493, February 2019, doi: 10.1016/j.egypro.2019.01.382.

[19] R. Rossi, "Design of a PMSM Field-Oriented Control Algorithm with Flux-Weakening for Battery Electric Vehicles," PhD dissertation, Politecnico di Torino, 2019.

[20] T. D. Do, H. H. Choi, and J. Jung, "Nonlinear Optimal DTC Design and Stability Analysis for Interior Permanent Magnet Synchronous Motor Drives," in IEEE/ASME Transactions on Mechatronics, vol. 20, no. 6, pp. 2716-2725, December 2015, doi: 10.1109/TMECH.2015.2426725.

[21] V. M. Bida, D. V. Samokhvalov, and F. S. Al-Mahturi, "PMSM vector control techniques-A survey," 2018 IEEE Conference of Russian Young Researchers in Electrical and Electronic Engineering (EIConRus), 2018, pp. 577581, doi: 10.1109/EIConRus.2018.8317164.

[22] J. S. Shamma, "Analysis and design of gain scheduled control systems," Ph.D. dissertation, M.I.T. Laboratory for Information and Decision Systems, Cambridge, MA, USA, 1988.

[23] J. S. Shamma and M. Athans, "Analysis of gain scheduled control for nonlinear plants," in IEEE Transactions on Automatic Control, vol. 35, no. 8, pp. 898-907, Aug. 1990, doi: 10.1109/9.58498.

[24] Y. Altun and K. Gulez, "Linear parameter varying control of permanent magnet synchronous motor via parameterdependent lyapunov function for electrical vehicles," 2012 IEEE International Conference on Vehicular Electronics and Safety (ICVES 2012), 2012, pp. 340-345, doi: 10.1109/ICVES.2012.6294262.

[25] L. Pohl and P. Blaha, "Linear parameter varying approach to robust control of a permanent magnet synchronous motor," 2011 15th IEEE International Conference on Intelligent Engineering Systems, 2011, pp. 287-291, doi: 10.1109/INES.2011.5954760.

[26] L. Pohl and L. Buchta, "Cascade Ho linear parameter varying control of PMSM," 2015 17th European Conference on Power Electronics and Applications (EPE'15 ECCE-Europe), 2015, pp. 1-8, doi: 10.1109/EPE.2015.7309320.

[27] L. Pohl and L. Vesely, "Robustness analysis of PMSM LPV controller," Proceedings of DAAAM conference, vol. 2011, 2011.

[28] A. Pahlavani, M. Reza, and H. Damroodi, "LPV Control for speed of permanent magnet synchronous motor (PMSM) with PWM Inverter," Journal of Electrical and Computer Engineering Innovations, vol. 4, no. 2, pp. 185193, 2016.

[29] H. Lee, Y. Lee, D. Shin, and C. C. Chung, "Hळ control based on LPV for load torque compensation of PMSM," 2015 15th International Conference on Control, Automation and Systems (ICCAS), 2015, pp. 1013-1018, doi: 10.1109/ICCAS.2015.7364794.

[30] H. Hwang, Y. Lee, D. Shin, and C. C. Chung, "H2 control based on LPV for speed control of permanent magnet synchronous motors," 2014 14th International Conference on Control, Automation and Systems (ICCAS 2014), 2014, pp. 922-927, doi: 10.1109/ICCAS.2014.6987916.

[31] L. Pohl, I. Vesely, and M. Graf, "Real-time implementation of $\mathscr{H} 00$ LPV controller for PMSM drive," IECON 201339th Annual Conference of the IEEE Industrial Electronics Society, 2013, pp. 3072-3077, doi: 10.1109/IECON.2013.6699619.

[32] W. Leonhard, "Control of Electrical Drives," Springer-Verlag third edition, Berlin, 2001

[33] P. C. Krause, O. Wasynczuk, S. D. Sudhoff, and S. Pekarek, "Analysis of Electric Machinery and Drive Systems," Wiley-IEEE Press; 2 edition, 2002

[34] N. P. Quang and Jörg-Andreas Dittrich, "Vector Control of Three-Phase AC Machines," Springer, Heidelberg Berlin, 2008

[35] K. Ogata and Y. Yang, “Modern control engineering,” Prentice hall, 2002. 